\title{
La programación infantil y juvenil de la televisión pública española: ¿oferta generalista o temática? El paso de La 2 a Clan TVE.
}

\author{
Erika FERNÁNDEZ GÓMEZ \\ Universidad Internacional de La Rioja \\ erika.fernandez@unir.net
}

Recibido: $12 / 07 / 2012$

Aceptado: 17/10/2012

\section{Resumen}

Dos etapas marcan la presencia del público infantil y juvenil ante la pequeña pantalla. En los 90 , con la llegada de las televisiones privadas el bloque de programación dirigido a esta audiencia fue muy competitivo. En cambio, la primera década del SXXI se caracterizó por los contenidos inadecuados que las cadenas generalistas programaban durante los horarios protegidos. Solo la segunda cadena pública española se diferenciaba por ofrecer espacios a estos espectadores en tres franjas horarias. Con la irrupción de la Televisión Digital Terrestre (TDT), este segmento se consideró nuevamente como target. Como consecuencia, la programación de La 2 se desplazó al nuevo canal temático, Clan TVE.

En este artículo se compara la parrilla de los dos canales públicos. Se pretende determinar en qué cadena niños y jóvenes están mejor atendidos.

Palabras clave: Televisión pública, TDT, niños, jóvenes, canal temático.

\section{The schedule of the Spanish public television aimed at children and youngsters. Is better a general offer or a thematic one? From La 2 to Clan TVE.}

\begin{abstract}
The Spanish television is characterized by two periods in which programmes were aimed at children and youngsters. The first stage was in the nineties with the arrival of the private channels. Nevertheless, the first decade of the 21 st century was portrayed by the unsuitable contents that television broadcast during protected schedule. Only the second public channel offered shows to this audience. As a result of the Digital Terrestrial Television arrival, kids and young people became into a target again. Therefore, the schedule of La 2 was moved to the new thematic channel, Clan TVE.

The goal of this paper is to compare the broadcast scheduling of the two public channels. The aim is to find the better propose to children and youngsters.

Keywords: Public broadcaster, Digital Terrestrial Television, children, young people, thematic channel.

\section{Referencia normalizada}

FERNÁNDEZ GÓMEZ, Erika (2012): “La programación infantil y juvenil de la televisión pública española: ¿oferta generalista o temática? El paso de La 2 a Clan TVE". Estudios sobre el mensaje periodístico. Vol. 18, núm. especial octubre, págs.: 313-323. Madrid, Servicio de Publicaciones de la Universidad Complutense.
\end{abstract}

Sumario: 1. Introducción. 2. Objetivos y metodología. 3. La programación infantil y juvenil: de la televisión generalista a la temática (2007-2010). 4. Análisis de La 2 y Clan TVE. 5. Conclusiones. 6. Referencias bibliográficas.

\section{Introducción}

La franja habitual dedicada a los niños fue muy competitiva al comienzo de las televisiones privadas en la década de los 90 (Cortés, 2001: 127). Pero, poco a poco, los operadores televisivos optaron por otros formatos menos apropiados para este seg- 
mento de la población con los que obtener más audiencia y, por lo tanto, más ingresos publicitarios.

En este contexto, el 16 de abril de 2007, la segunda cadena de Televisión Española puso en marcha su nueva parrilla de programación primaveral con el eslogan: $\mathrm{La} 2 \mathrm{Se}$ Mueve. Un ambicioso proyecto que pretendía dotar de competitividad al segundo canal público para que dejara así de ser "para una inmensa minoría" y que sobre todo, perseguía acercarse al público joven (Gabinete de Prensa de RTVE, 2007: web) ${ }^{1}$.

Aunque la televisión generalista no orientaba su programación hacia el público infantil y juvenil, un año más tarde de la iniciativa de La 2, varios canales encontraron en la Televisión Digital Terrestre (TDT) un aliado para satisfacer esta demanda y diversificar así su negocio ${ }^{2}$. Niños y jóvenes comenzaron a constituir una nueva audiencia objetivo para las viejas cadenas en nuevas pantallas temáticas. A la oferta de Clan (TVE), Neox (Antena 3) y Disney Channel se unió el nuevo canal infantil de Telecinco (Boing).

Con el apagón analógico llevado a cabo el 3 de abril de 2010, el sistema de emisión de todas las cadenas pasó a ser digital. Y la irrupción de los canales temáticos originó que Televisión Española buscase una nueva estrategia para La 2. Así, tras tratar de acercarse al público joven, el 15 de septiembre de 2010, se anunció la vuelta a los orígenes para este canal. De nuevo, sería una cadena cultural y para minorías, en la que la programación infantil no tenía lugar. Esta audiencia sería cubierta por Clan, el canal temático para niños y jóvenes de la televisión pública en la TDT (Fórmula TV, 2010: web).

Ante este nuevo panorama, resulta necesario preguntarse si estos canales especializados ofrecen una oferta de calidad y variada al target al que se dirigen.

\section{Objetivos y metodología}

El estudio parte de la siguiente pregunta: ¿se encuentra el público infantil y juvenil mejor atendido a través de un canal temático que de uno generalista?

Para dar respuesta esta cuestión, se ha llevado a cabo un análisis comparativo de la programación de La 2 y Clan, dos canales pertenecientes a la Corporación RTVE.

La investigación se ha llevado a cabo desde una perspectiva cualitativa al observar, describir y explicar la programación de las dos cadenas a través de un elemento clave: la construcción de la parrilla.

El objetivo es determinar si la oferta del canal temático es de calidad ${ }^{3}$ y variada, si se adecua al público al que se dirige así como identificar algunos de los retos a los que la televisión pública deberá hacer frente en los próximos años si quiere seguir ocupando un hueco entre una de las audiencias más especiales, económicamente rentables y nacida online (Bringué y Sádaba, 2009: 15).

1 El cambio se enmarca en el primer año de existencia de la Corporación RTVE, la cual comenzó su andadura el 15 de enero de 2007 tras veintisiete años del Ente Público RTVE.

2 El Plan Nacional de Transición a la TDT del 2007 apostaba por el acceso general y gratuito (Zallo, 2011: 51).

3 Entendiendo como calidad aquellos contenidos que responden a los principios que guían la programación de servicio público en España y que se encuentran recogidos en la Ley 17/2006, de 5 de junio, de la radio y la televisión de titularidad estatal. En concreto, para este estudio se considera el criterio de que la producción propia debe tener un peso sustancial en 
De modo que se plantea la siguiente hipótesis: el público infantil y juvenil dispone de una oferta variada y de calidad en la programación del canal temático Clan TVE.

Para realizar el análisis se ha tenido en cuenta la programación ofrecida por los dos canales en dos etapas que marcan el consumo televisivo (Contreras y Palacio, 2003: 134-135).

Por un lado, para Clan se incluye una muestra representativa de un día laborable correspondiente al mes de diciembre de 2010. En esta época, el público se encuentra de vacaciones y las condiciones climatológicas invitan a quedarse en casa a consumir el medio. En el caso de La 2, se ha tomado un día de la oferta emitida en noviembre de 2008. Se trata de un período en el que su parrilla reflejaba los resultados de la reestructuración anunciada en abril de 2007.

\section{La programación infantil y juvenil: de la televisión generalista a la temática (2007-2010)}

La televisión siempre ha sido el medio líder en audiencia (AIMC, 2012: 3) y en inversión publicitaria del mercado español (Infoadex, 2012: 10). Sin embargo, en los últimos años ha sido la red la que mayor crecimiento ha experimentado. A este hecho, hay que añadir los cambios a los que la pequeña pantalla ha tenido que hacer frente con la llegada de la televisión digital terrestre.

La etapa previa a la implantación de la TDT, se caracterizó por la ausencia de una propuesta atractiva y competitiva para niños y jóvenes de la que disfrutar en la televisión generalista. Programas del corazón y realities impregnaron la oferta de todas las cadenas, pues son formatos que proporcionan un mayor número de espectadores y, por lo tanto, atraen más inversión publicitaria. Una forma de hacer televisión que muchos han coincidido en denominar "telebasura" y que tuvo como consecuencia que, esta audiencia, acabase por consumir productos que ni eran convenientes para su edad, ni satisfacían sus necesidades de ocio y formación. Las quejas por parte de asociaciones de padres y consumidores fueron constantes ante los contenidos inadecuados que las cadenas generalistas programaban durante los horarios protegidos ${ }^{5}$.

el conjunto de la programación de RTVE y apoyar de manera activa a la industria audiovisual nacional. Por otro lado, el deber de la Corporación de atender específicamente a los colectivos sociales que requieran una atención específica como la infancia y la juventud. Lo cual se hará tanto en el número de horas de emisión como en la producción de contenidos adecuados a las diferentes edades, protegiendo el libre desarrollo de la personalidad y el resto de derechos de los menores. También tiene el deber de velar por el público juvenil, programando contenidos que animen al conocimiento y la formación junto a una oferta atractiva de entretenimiento creativo e innovador.

4 Entendiendo por ésta a la televisión basada en programas de ínfima calidad que buscan en lo escandaloso o lo morboso el favor del público (Cortés, 2001: 269).

5 En 2007, año en que La 2 decidió apostar por la audiencia infantil y juvenil, se recogieron 359 quejas en torno al incumplimiento del Código de Autorregulación sobre Contenidos Televisivos en Infancia por parte de las principales cadenas (Comisión Mixta de Seguimiento, 2007: web). 
Con el apagón analógico (2010), el sistema de emisión de todas las cadenas pasó a ser digital. Las cadenas autonómicas, locales y nacionales generalistas que emitían a través del sistema terrestre analógico constituyeron la TDT. Esta nueva televisión esbozaba una oferta más amplia y en la que cada uno de los operadores dispondría de más de un canal. Con lo que se incrementó todavía más la competencia y la segmentación de audiencias.

Si bien, la televisión digital terrestre contó con unos años previos de adaptación a través de los cuáles los espectadores fueron familiarizándose con sus contenidos (Plan Nacional de Transición a la TDT de 2007). Una de las principales novedades que supuso este nuevo sistema de emisión fue la introducción de canales temáticos en abierto dirigidos a niños y jóvenes por parte de viejos operadores.

Así, ya en 2008, los canales más vistos en la televisión digital terrestre fueron Neox, Clan y Nova (XL Semanal, 2008: 14-15). La primera y la última conforman la oferta digital de Antena 3 dedicados al público juvenil y ocio para toda la familia. En ese año, lo llamativo de los datos de share fue que encabezaron la lista en cuanto a cuota de pantalla gracias a su programación infantil y juvenil. Demostrando que, en ese momento, los más pequeños eran quiénes se apoderaban del mando de la nueva pantalla ante la ausencia de una oferta específica por parte de las cadenas generalistas.

El 1 de julio de 2008, a la oferta de Neox y Clan se sumó la competencia de uno de los grandes, Disney Channel. Estaba constituida por series y dibujos de éxitos a través del sello de la compañía multinacional de entretenimiento Disney. Una de las razones por las que este canal se lanzó en abierto -que hasta el momento se ofrecía sólo a través de las plataformas ADSL, cable y satélite-, fue para dar respuesta a la gran demanda de programación infantil que había en ese momento en España.

De hecho, el $72 \%$ de las familias españolas se interesó en adoptar un sintonizador de TDT en sus hogares por los contenidos infantiles que ofrecía (La Guia TV, 2008: web). Como titulaba el diario $A B C$ : "Siete de cada diez familias se "pasan" a la TDT por su oferta infantil" ( $A B C, 2008)$.

En este sentido, el orientar la programación a una audiencia específica es un fenómeno que en España se ha desarrollado con la llegada de la televisión digital terrestre pero que, en otros países como Estados Unidos comenzó en 1987 y se desarrolló a lo largo de los 90 .

Esta estrategia, conocida como narrowcasting (difusión selectiva), nació como alternativa para competir con las tres grandes cadenas del panorama televisivo. CBS, NBC y ABC poseían relaciones sólidas con los anunciantes (Perebinossoff et. al. 2005: 16-17). De modo que, mientras la estrategia de las majors era buscar las audiencias lo más amplias posibles, las nuevas cadenas optaron por un pequeño y definido segmento de los mercados. Por ejemplo, The WB -hoy conocida como The CW- se dirigió a los teens ${ }^{6}$.

${ }^{6}$ Chicos y chicas de entre 8 y 14 años que viven y respiran ídolos y que constituyen uno de los mercados demográficos más importantes del mundo (Andrews, 2009: 18). 


\section{Análisis de La 2 y Clan TVE}

\subsection{La programación infantil y juvenil de La 2 de TVE}

La oferta de La 2 en 2008 se caracterizó por la existencia de tres bandas horarias dirigidas al público infantil y juvenil. Esta oferta presentaba la particularidad de estar agrupada bajo tres programas contenedores de producción nacional y en los que se combinaban animaciones de diferente origen. Solamente dos programas aparecían en la parrilla de manera autónoma.

Así, en la franja despertador se emitía el espacio de producción propia de divulgación de la ciencia Leonart (Tabla 1). A continuación se programaba el contenedor Los Lunnis, dirigido especialmente a los preescolares. A la hora de la comida, los escolares podían disfrutar de los contenidos emitidos en Comecaminos $^{7}$. Por la tarde, los jóvenes contaban con En Construcción. Por último, el bloque infantil-juvenil terminaba con la serie Smallville.

Destaca la oferta formativa de las series emitidas dentro de Los Lunnis. En el caso de los contenedores de mediodía y de tarde se caracterizan por los contenidos que pretenden divertir a los espectadores, aunque también se incluyen secciones de producción propia en las que se busca informarles y formarles.

Se trata por tanto, de una oferta que cubre los diferentes segmentos de población infantil y juvenil.

Tabla 1. Relación de programas emitidos en La 2 de TVE. Jueves, 20 de noviembre de 2008.

\begin{tabular}{|l|l|l|l|}
\hline Programa & Producción & Target & Tipo \\
\hline 1. Leonart & Propia & $\begin{array}{l}\text { Escolar (9- } \\
13 \text { años) }\end{array}$ & Formativo \\
\hline 2. Los Lunnis: & Propia/ajena & $\begin{array}{l}\text { Preescolar } \\
(2-7 \text { años) }\end{array}$ & $\begin{array}{l}\text { Entretenimiento- } \\
\text { formativo }\end{array}$ \\
- Los Lunnis: La serie & & \\
- Las aventuras de Lunicef & & \\
- La odisea de Los Lunnis & & \\
- El jardín de los sueños & & & \\
- Bernillou & & & \\
- Clifford & & & \\
\hline 3. Comecaminos: & & Preescolar- & Entretenimiento- \\
- Zorori, el extraordinario & & formativo \\
- Ben 10 & & & \\
- El búho & & & \\
- Pacific Blue & & & \\
\hline
\end{tabular}

${ }^{7}$ Espacio encargado a la productora española SelectaVisión. 


\begin{tabular}{|l|l|l|l|}
\hline 4. En Construcción: & Propia/ajena & $\begin{array}{l}\text { Escolar- } \\
\text { adolescente } \\
\text { - Las chicas Gilmore } \\
\text { - GomaespumEnglish } \\
\text { - Buffy, cazavampiros } \\
\text { - Dos hombres y medio }\end{array}$ & $\begin{array}{l}\text { Entretenimiento- } \\
\text { formativo }\end{array}$ \\
\hline 5. Smallville & Ajena & $\begin{array}{l}\text { Escolar- } \\
\text { adolescente } \\
\text { (a partir de } \\
7 \text { años })\end{array}$ & Entretenimiento \\
\hline
\end{tabular}

Fuente: elaboración propia

\subsection{La programación del canal temático Clan TVE}

Como ya se destacó, en 2010 se eliminó por completo la programación infantil y juvenil de La 2. Así, se desplazó a Clan por ser el segundo canal con mayor audiencia de Televisión Española ${ }^{8}$.

Al tratarse de un canal temático, la oferta para esta audiencia abarca el conjunto de la programación. Si bien, el análisis de la parrilla del canal temático muestra como se cubren las horas de programación con repeticiones de espacios.

Tomando como referencia la programación del jueves, 30 de diciembre de 2010, se observa como de los 50 programas que ofreció ese día, sólo de nueve productos se emite un único pase al día (señalados en negrita en la Tabla 2).

Así, únicamente ocho programas constituyeron una novedad para los niños y en el caso de los jóvenes, la primicia se redujo a un espacio ( $i$ Carly). Además, animaciones como Ya llega Noddy, Gormiti o Dora la exploradora contaron con tres emisiones diarias.

Los últimos pases del día pertenecen a series de ficción nacional de La 1, y por lo tanto, que comprenden a un público adulto (Águila Roja9 o Cuéntame cómo pasó). En el caso de Smallville se trata de un producto que ya estaba en La 2. De Hércules, se pasaron reruns ya que, la serie terminó de emitirse en España por el primer canal público en 2002. Vemos por lo tanto como es una manera de sacar partido a la $l i$ brary $^{10}$.

Otro de los aspectos que sobresalen es que, el canal es infantil, es decir, para preescolares y escolares. Aunque destacan los espacios dirigidos a este último grupo. De los 50 programas presentes en la programación analizada, sólo uno constituye una oferta específica y novedosa para el público juvenil. iCarly, es una serie del canal es-

8 En el primer mes de apagón analógico, por primera vez una cadena generalista igualó en cuota de audiencia mensual a otra exclusiva de la TDT. La 2, con un mínimo histórico de cuota $(3,1 \%)$, registró la misma audiencia que Clan TVE (Europa Press, 2010: web).

9 Serie de aventuras programada por La 1 en horario de máxima audiencia y clasificada por RTVE como no recomendada para menores de 13 años.

10 Siguiendo a J.A. Cortés $(2001,156)$, la library es el catálogo total de programas cuyos derechos de emisión están vigentes y se pueden emitir en la cadena. 
tadounidense Nickelodeon que se estrenó en marzo de 2010 en el canal temático y que tiene como protagonista a una chica de 13 años. La serie se emitió en el prime time, a las 22.00 horas de la noche y comprende una audiencia de entre 12 y 17 años.

Asimismo, Fórmula TV publicó el 3 de enero de 2010 que, Clan es el canal líder entre el público infantil de 4 a 12 años. Bob Esponja, los famosos dibujos de Nickelodeon, es el mayor atractivo y constituye la serie más vista. En la Tabla 2 puede verse como el día analizado ocupa hasta cuatro huecos en la parrilla. De forma que se deja de lado a un grupo que, especialmente en el caso de una televisión pública, se debe prestar especial dedicación.

Si se compara con la programación que poseía La 2 (Tabla 1), se puede ver cómo, aunque el público infantil era el preferido por la cadena por esta presente en varios bloques de programación, los jóvenes contaban con una franja específica. Por las tardes se les ofrecía el contenedor de producción propia En Construcción, constituido también por series de ficción extranjera y que continuaba con la emisión de Smallville.

También se aprecia como Clan heredó contenidos programados por la segunda cadena en el año 2008 como Los Lunnis, Pocoyó, Caillou y Berni.

Por otro lado, más de la mitad de los espacios programados tienen como finalidad entretener a la audiencia (28), frente a los que pretenden formarles (22). De hecho, los formativos se caracterizan por dirigirse a los preescolares. Los preescolares cuentan con dieciséis espacios específicos para ellos. En el caso de los escolares, se reduce a un par. De los otros cuatro espacios formativos restantes, dos se dirigen tanto a preescolares como escolares y otros dos a los bebés que comienzan andar y a hablar.

Por último, en la parrilla del canal temático destaca la apuesta por series que se compran en el mercado internacional frente a las producidas por la propia cadena o encargadas a productoras nacionales.

Tabla 2. Relación de programas emitidos en Clan TVE. Jueves, 30 de diciembre de 2010.

\begin{tabular}{|l|l|l|l|}
\hline \multicolumn{1}{|c|}{ Programa } & \multicolumn{1}{c|}{ Producción } & \multicolumn{1}{c|}{ Target } & \multicolumn{1}{c|}{ Tipo } \\
\hline 1. Hércules & Ajena & Todos los públicos & Entretenimiento \\
\hline 2. Sandra, detective de cuentos & Coproducción & Escolar & Entretenimiento \\
\hline 3. Dora la exploradora & Ajena & Preescolar & Formativo \\
\hline 4. Las tres mellizas & Ajena & Preescolar & Formativo \\
\hline 5. Ya llega Noddy & Ajena & Preescolar & Formativo \\
\hline 6. Los Lunnis & Propia & Preescolar & Formativo \\
\hline 7. El jardín de los sueños & Ajena & Preescolar & Formativo \\
\hline 8. Pocoyó & Ajena (nacional) & Preescolar & Formativo \\
\hline 9. Dougie se disfraza & Ajena & Preescolar & Formativo \\
\hline 10.Juega conmigo & Ajena & Preescolar & Formativo \\
\hline 11. Dora la exploradora & Ajena & Preescolar & Formativo \\
\hline 12. Caillou & Ajena & Preescolar & Formativo \\
\hline 13. Gourmiti & Ajena & Escolar & Entretenimiento \\
\hline 14. Bob Esponja & Ajena & Escolar & Entretenimiento \\
\hline
\end{tabular}




\begin{tabular}{|c|c|c|c|}
\hline Programa & Producción & Target & Tipo \\
\hline 15. Batman & Ajena & Escolar & Entretenimiento \\
\hline 16. Ya llega Noddy & Ajena & Preescolar & Formativo \\
\hline 17. El tiovivo Mágico & Ajena & Escolar & Entretenimiento \\
\hline 18. Jim Jam\& Sunny & Ajena & Preescolar & Formativo \\
\hline 19. Sandra, detective de cuentos & Coproducción & Escolar & Entretenimiento \\
\hline 20. Winx Club & Ajena & Escolar & Entretenimiento \\
\hline 21. Lazy Town & Ajena & $\begin{array}{l}\text { Preescolar-escolar } \\
\text { (2-10 años) }\end{array}$ & Formativo \\
\hline 22. Baby Looney Tunes & Ajena & Toddlers $^{11}$ & Formativo \\
\hline 23. Gormiti & Ajena & Escolar & Entretenimiento \\
\hline 24. La Liga de la Justicia & Ajena & Escolar & Entretenimiento \\
\hline 25. Berni & Ajena (nacional) & Escolar & Formativo \\
\hline 26. Bob Esponja & Ajena & Escolar & Entretenimiento \\
\hline 27. Dora la Exploradora & Ajena & Preescolar & Formativo \\
\hline 28. Ya llega Nody & Ajena & Preescolar & Formativo \\
\hline 29. Dora la exploradora & Ajena & Preescolar & Formativo \\
\hline 30. Jim Jam\& Sunny & Ajena & Preescolar & Formativo \\
\hline 31. Baby Looney Tunes & Ajena & Toddlers & Formativo \\
\hline 32. El Tiovivo Mágico & Ajena & Escolar & Entretenimiento \\
\hline 33. Sandra, detective de cuentos & Coproducción & Escolar & Entretenimiento \\
\hline 34. Lazy Town & Ajena & $\begin{array}{l}\text { Preescolar-escolar } \\
\quad(2-10 \text { años })\end{array}$ & Formativo \\
\hline 35. Pokémon & Ajena & Escolar & Entretenimiento \\
\hline 36. Winx Club & Ajena & Escolar & Entretenimiento \\
\hline 37. La Liga de la Justicia & Ajena & Escolar & Entretenimiento \\
\hline 38. Gormiti & Ajena & Escolar & Entretenimiento \\
\hline 39. Batman & Ajena & Escolar & Entretenimiento \\
\hline 40. Berni & Ajena (nacional) & Escolar & Formativo \\
\hline 41. Bob Esponja & Ajena & Escolar & Entretenimiento \\
\hline 42. Gormiti & Ajena & Escolar & Entretenimiento \\
\hline 43. Bob Esponja & Ajena & Escolar & \begin{tabular}{|l|} 
Entretenimiento \\
\end{tabular} \\
\hline 44. iCarly & Ajena & $\begin{array}{l}\text { Adolescente (12- } \\
17 \text { años) }\end{array}$ & Entretenimiento \\
\hline 45. Smallville & Ajena & \begin{tabular}{|c} 
Escolar-adoles- \\
cente (a partir de 7 \\
años) \\
\end{tabular} & Entretenimiento \\
\hline
\end{tabular}

${ }^{11}$ Término inglés con el que se define a los bebés que comienzan a andar (Dafna, 2007: 38) 


\begin{tabular}{|l|l|c|l|}
\hline \multicolumn{1}{|c|}{ Programa } & \multicolumn{1}{|c|}{ Producción } & Target & \multicolumn{1}{c|}{ Tipo } \\
\hline 46. Hércules & Ajena & $\begin{array}{c}\text { Adolescente- } \\
\text { adulto }\end{array}$ & Entretenimiento \\
\hline 47. Smallville & Ajena & $\begin{array}{c}\text { Escolar-adoles- } \\
\text { cente (a partir de 7 } \\
\text { años) }\end{array}$ & Entretenimiento \\
\hline 48. Aguila Roja & Externa (La 1) & $\begin{array}{c}\text { Adolescente-adul- } \\
\text { tos (13 años en ade- } \\
\text { lante) }\end{array}$ & Entretenimiento \\
\hline 49. Cuéntame cómo pasó & Externa (La 1) & Todos los públicos & Entretenimiento \\
\hline 50. Cuéntame cómo pasó & Externa (La 1) & Todos los públicos & Entretenimiento \\
\hline
\end{tabular}

Fuente: elaboración propia

\section{Conclusiones}

El análisis de la oferta para el público infantil y juvenil de la televisión generalista La 2 y el canal temático Clan, pone de manifiesto tres aspectos de especial relevancia.

1. En primer lugar, la TDT no ha traído la diversidad de contenidos que prometía, sino que se ha convertido en una manera de sacar partido a la library de las cadenas.

2. En segundo, con la apuesta de Televisión Española por Clan se ha dejado de lado a una de las audiencias por las que también tiene el derecho de velar, los adolescentes.

3. En tercer lugar, la oferta del canal público se base en animaciones y series de ficción extranjeras cuya finalidad principal es el entretenimiento. Como servicio público deben primar los contenidos de producción propia que contribuyan al conocimiento.

De modo que, se refuta la hipótesis de partida. No todos los segmentos que comprende el público infantil y juvenil disponen de una oferta variada y de calidad en el canal temático. Clan TVE presenta una amplia oferta formativa a preescolares, reducida para los escolares y carente para los adolescentes.

Así, aunque en la actualidad los niños cuentan con diferentes canales especializados, tanto padres como asociaciones de telespectadores e investigadores deben mantener una actitud crítica respecto a los contenidos que en ellos se emiten.

Esta televisión conlleva una forma de consumir contenidos diferentes a la generalista. Funciona como un reproductor de DVD o disco multimedia y, por lo tanto, no hay diferenciación en épocas especiales. Atrás se quedan las televisiones que amplían su oferta infantil y juvenil en Navidades o vacaciones de Semana Santa y verano.

En este sentido, tampoco hay diferencia con el servicio de televisión a la carta a través de la red, pues en el caso de Clan, los niños disponen de un portal en el que acceder a sus contenidos favoritos. Además, la web ofrece otros añadidos como, los juegos ${ }^{12}$.

12 Televisión Española puso en marcha El Portal Infantil Clan en junio de 2009 (http://www.rtve.es/infantil/). 
Por lo que se considera que las televisiones deben tener una actitud vigilante si no quieren que esta audiencia se desplace definitivamente a la pantalla de su ordenador o bien, se construya definitivamente su propia parrilla de programación.

Para terminar debe destacarse también el lado positivo de la TDT. En primer lugar, porque el desarrollo de canales específicos para este público permite alejarlos de los riesgos de los contenidos de las televisiones generalistas. $\mathrm{Y}$ en segundo lugar, suponen un nuevo recurso educativo para los espectadores. Esta nueva televisión posibilita que los contenidos se puedan ver en su versión original y con subtítulos en español, fomentando de esta manera el aprendizaje de una segunda lengua. Por ejemplo, en la web de Clan TVE, los niños pueden disfrutar de sus series infantiles en inglés, incluida la española Pocoyó.

\section{Referencias bibliográficas}

ABC (2008): "Siete de cada familias se pasan a la TDT por su oferta infantil", en $A B C, 16$ de noviembre. http://www.abc.es/20081116/radio-television-series/siete-cadadiez-familias-20081116.html. [Fecha de consulta: 18 de mayo de 2010].

AIMC (2012): Resumen general de resultados EGM. Octubre de 2011 a mayo de 2012. $\mathrm{http}: / /$ www.aimc.es/-Datos-EGM-Resumen-General-html [Fecha de consulta: $17 \mathrm{de} \mathrm{oc-}$ tubre de 2012]

ANDREWS, Amanda (2009): “Tweens, no tweets", en Marketing Magazine, 29 de abril. Reino Unido, p.18.

BRINGUÉ SALA, Xavier y SÁDABA CHALEZQUER, Charo (2009): La Generación interactiva en España: niños y adolescentes ante las pantallas. Barcelona, Ariel-Fundación Telefónica.

CONTRERAS, José Miguel y PALACIO, Manuel (2003): La programación de televisión. Madrid, Editorial Síntesis.

COMISIÓN MIXTA DE SEGUIMIENTO (2007): Informe de evaluación sobre la aplicación del Código de Autorregulación de Contenidos Televisivos e Infancia $\left(2^{\circ}\right.$ año). http://www.tvinfancia.es/Informes/InformeAnual2007.htm. [Fecha de consulta: 17 de octubre de 2012].

CORTÉS, José Ángel (2001): La estrategia de la seducción. La programación en la neotelevisión (segunda edición). Pamplona, Universidad de Navarra.

ESPAÑA. Ley 17/2006, de 5 de junio, de la radio y televisión de titularidad estatal. Boletín Oficial de Estado, 6 de junio de 2006, núm. 134, p. 21207.

EUROPA PRESS (2010): “Clan TVE alcanza a una cadena generalista”. http://www.europapress.es/chance/tv/noticia-clan-tve-alcanza-cadena-generalista-20100503110600.html [Fecha de consulta: 18 de octubre de 2012].

FÓRMULA TV (2010): "La 2 de TVE elimina toda su programación infantil a partir del 15 de septiembre". 5 de septiembre. http://www.formulatv.com /1,,16240,1.html. [Fecha de consulta: 5 de septiembre de 2010]. 
FÓRMULA TV (2010): “Clan lidera la TDT con 'Bob Esponja' como mayor atractivo". 3 de enero. http://www.formulatv.com/noticias/17770/clan-sigue-frente-tdt-bobesponja-como-mayor-atractivo/. [Fecha de consulta: 3 de enero de 2010].

GABINETE DE PRENSA DE RTVE (2007): Dossier de prensa La 2 Se Mueve. 13 de abril. http://www.rtve.es/files/1013-984-FICHERO/La2_07DosierPDF.pdf?download=1. [Fecha de consulta: 23 de septiembre de 2010].

INFOADEX (2012): Resumen Estudio Infoadex de la Inversión Publicitaria en España 2012. http://www.infoadex.es/RESUMEN\%202012.pdf [Fecha de consulta: 17 de octubre de 2012]

LA GUÍA TV (2008): "Según Disney Channel, los contenidos infantiles impulsan la TDT". 14 de noviembre. [Fecha de consulta: 10 de mayo de 2010].

PEREBINOSSOFF, Philippe; GROSS, Brian; y GROSS, Lynne S. (2005): Programming for Tv, Radio \& Internet. Strategy, Development \& Evaluation (segunda edición). Burlington (EE.UU), Editorial Elsevier.

RTVE (2011): “'iCarly' y sus amigos estrenan este martes en Clan sus nuevas aventuras en RTVE.es". 19 de septiembre. http://www.rtve.es/rtve/20110919/icarly-sus-amigos-estrenan-este-martes-clan-sus-nuevas-aventuras/462546.shtml. [Fecha de consulta: 2 de octubre de 2011].

WEB OFICIAL CLAN TVE: www.rtve.es/infantil. [Fecha de consulta: 17 de octubre de 2012].

ZALLO, Ramón (2011): "Políticas de comunicación audiovisual en (y para después de) la crisis económica en España", en CAMPOS FREIRE, Francisco (coord.): El nuevo escenario mediático. Zamora, Comunicación Social Ediciones y Publicaciones, pp.49-80.

\section{$\overline{\text { Erika FERNÁNDEZ GÓMEZ }}$}

erika.fernandez@unir.net

Universidad Internacional de La Rioja (UNIR)

Gran Vía Rey Juan Carlos I, 41. C.P. 26002, Logroño (La Rioja)

Profesora Ayudante del Grado en Comunicación y Profesora del Máster en Creación de Guiones Audiovisuales de UNIR. Doctora, con mención europea, en Publicidad y Relaciones Públicas por la Universidad de Vigo. 